\title{
O PERFIL DOS EGRESSOS DE ENGENHARIA MECÂNICA FORMADOS PELO PPC DE 2004: ANÁLISE SOBRE ASPECTOS SOCIOECONÔMICOS E SUAS PERCEPÇÕES
}

\author{
THE PROFILE OF MECHANICAL ENGINEERING GRADUATES BY THE 2004 PPC: \\ ANALYSIS OF SOCIO-ECONOMIC ASPECTS AND THEIR PERCEPTIONS
}

Pedro Vitor Teixeira Ribeiro ${ }^{1}$, Victor Hugo Rodrigues Nogueira George², Rômulo do Nascimento Rodrigues ${ }^{3}$, Roberto de Araújo Bezerra ${ }^{4}$, Pierre Maurice Christophe Lamary ${ }^{5}$

DOI: 10.37702/REE2236-0158.v40p437-448.2021

\begin{abstract}
RESUMO
Com a elaboração do novo Projeto Pedagógico de Curso (PPC) da graduação em Engenharia Mecânica da Universidade Federal do Ceará (UFC) para 2020 e a necessidade de o mesmo refletir com eficácia um panorama moderno de ensino de engenharia e as expectativas do mercado para a formação de novos profissionais, o presente trabalho foi desenvolvido visando avaliar as percepções de alunos formados durante a vigência do PPC de 2004 sobre a qualidade da formação do engenheiro mecânico da UFC, bem como possibilidades de modernização e melhoria do ensino. Para isso, foi feita uma revisão bibliográfica e foram coletados dados sobre os alunos formados que ingressaram a partir de 2005, por meio de um questionário online composto de 26 perguntas. O questionário utilizado foi adaptado de trabalhos pesquisados, visando garantir certo direcionamento e padronização. Os dados obtidos pela pesquisa revelaram um egresso bem inserido no mercado de trabalho (cerca de $81 \%$ ), porém, insatisfeito com as condições de trabalho na área, principalmente quanto às oportunidades de carreira e remuneração, e que faz algumas críticas à estrutura curricular do curso, apontando deficiências e pontos a se melhorar. Com suas opiniões e sugestões, foram elencadas algumas propostas para atingir esse objetivo.
\end{abstract}

Palavras-chave: Engenharia Mecânica; avaliação da graduação; perfil do egresso.

\begin{abstract}
Bearing in mind the development of the new curricular project of the course (PPC) of the Mechanical Engineering course of Federal University of Ceará (UFC) for the year 2020 and the necessity of it to effectively reflect a modern overview of engineering education and market expectations for the qualification of new professionals, this work was developed aiming to evaluate the perceptions of students who graduated under the validity of the 2004 PPC about the quality of the qualification of the mechanical engineer from UFC, as well as possibilities of modernization and improvement of teaching. In this sense, a literature review was made and data were collected about the graduates who enrolled the course from 2005 until the present year, through an online questionnaire comprised of 26 questions. For that, the questionnaire used was adapted from researched works, in order to ensure a certain direction and standardization. The data obtained by the research revealed a well inserted graduate in the job market, with circa $81 \%$ of them working, however, dissatisfied with the working conditions in the field, mostly having to do with career opportunities and wages, and that makes some

\footnotetext{
${ }^{1}$ Engenheiro Mecânico, Universidade Federal do Ceará (UFC), ribeiro.tpedro@gmail.com

${ }^{2}$ Discente de Engenharia Mecânica, Universidade Federal do Ceará (UFC), victorhugogeorge@ alu.ufc.br

${ }^{3}$ Prof. Dr. e Coordenador do Curso de Engenharia Mecânica, Universidade Federal do Ceará (UFC), rrodrigues@ufc.br

${ }^{4}$ Prof. Dr. do Curso de Engenharia Mecânica, Universidade Federal do Ceará (UFC), roberto.bezerra@ufc.br

${ }^{5}$ Prof. Dr. do Curso de Engenharia Mecânica, Universidade Federal do Ceará (UFC), pierre.lamary@ufc.br
} 
criticism to the course curricular structure, pointing out deficiencies and points for improvement. With their opinions and suggestions, some proposals were listed to achieve this goal.

Keywords: Mechanical Engineering; course evaluation; alumni profile.

\section{INTRODUÇÃO}

As perspectivas profissionais para engenheiros mecânicos nos últimos anos têm se alterado de diversas maneiras e, frequentemente, é possível perceber que, apesar de existirem diversas possibilidades de carreira, os caminhos para uma formação sólida e condizente com os paradigmas sociais e econômicos de hoje não são evidentes para os graduandos. Durante a vivência acadêmica, alunos relatam dificuldades para ingressar em empregos ou estágios devido à escassez de vagas, alta concorrência, por não conseguirem atender ao perfil exigido pelas empresas, além de falta de flexibilidade na conciliação de estudo e trabalho.

É clara a necessidade da modernização das estruturas curriculares para fazer frente às mudanças e expectativas do mercado e, apesar de serem visíveis iniciativas nesse sentido, esse processo tem se mostrado lento (LOPES, 2002). Posto isso, pode-se levantar os seguintes questionamentos: a Universidade Federal do Ceará está preparando adequadamente os seus alunos de Engenharia Mecânica para o mercado? O Projeto Pedagógico de Curso aborda questões modernas e atuais para formar engenheiros mais capazes e multidisciplinares? Para isso, buscaram-se as opiniões e sugestões de ex-alunos do curso, para que pudessem comparar suas experiências na carreira com o proposto pelo PPC, com objetivo de entender, pelos relatos de quem vivência atualmente e de perto o mercado, as forças e fraquezas do currículo atual.

\section{METODOLOGIA}

O presente trabalho se baseou no trabalho desenvolvido por Chaves (2016), utilizado em seu Trabalho de Conclusão de Curso no curso de graduação em Engenharia de Produção da
UFC. A partir do questionário desenvolvido por Chaves (2016), e para adequá-lo ao novo objeto de estudo, a saber, o curso de graduação em Engenharia Mecânica, foram feitas algumas adaptações, porém mantendo a sua base fundamental, para que pudessem ser feitas comparações. A coleta de informações se deu pelo envio on-line do questionário, criado pela ferramenta Google Forms, via e-mail ou contato direto com os egressos, cujas informações de contato foram obtidas através do Sistema Integrado de Gestão de Atividades Acadêmicas (SIGAA), com uma lista de alunos formados.

Foi feita a revisão bibliográfica sobre o tema da formação do engenheiro direcionada para as demandas do mercado moderno em livros, artigos e outras dissertações, além de realizar pesquisa sobre os Referenciais Nacionais e às Diretrizes Curriculares Nacionais dos cursos de graduação em engenharia. Para entender o histórico do curso, recorreu-se tanto à leitura do Projeto Pedagógico de Curso quanto à pesquisa documental em portais de outras universidades, livros sobre a história da engenharia e ao livro de memórias do Cinquentenário da Escola de Engenharia da UFC.

\section{Engenharia Mecânica na UFC}

A Engenharia Mecânica está intimamente relacionada aos processos produtivos $\mathrm{e}$ desenvolvimento de tecnologias, atuando em conjunto com todos os outros ramos para atingir objetivos e resolver problemas.

$\mathrm{O}$ curso de Engenharia Mecânica vem crescendo e se desenvolvendo desde a fundação da Escola de Engenharia em 1955, inclusive com a recente criação da graduação em engenharia mecânica no campus de Russas da Universidade Federal do Ceará, em 22 de julho de 2014, pela resolução $n^{\circ} 12 / C O N S U N I$ da 
UFC. Atualmente, são admitidos 60 alunos por ano em Fortaleza, tendo o curso, desde sua criação, formado mais de mil profissionais.

\section{O perfil do engenheiro moderno}

A universidade tem papel fundamental na formação de profissionais, no entanto, esse dever carrega consigo também o desafio de garantir um alinhamento entre o que se espera de seus egressos e a instrução que lhes é dada. $\mathrm{O}$ mercado, que absorve a grande maioria dos profissionais como força de trabalho, porém, não é imutável. O progresso tecnológico e social influencia diretamente as necessidades das empresas, sendo assim, o perfil de empregado desejado também se altera com o passar do tempo.

Wickert e Lewis (2016) afirmam que, hoje, tal perfil buscado pressupõe habilidades além dos conhecimentos tradicionais técnicos e científicos. As novas exigências do comércio e do consumo requerem habilidades $e$ capacidades muitas vezes inter ou multidisciplinares (PÓVOA; BENTO, 2005), que fogem de uma visão puramente tecnicista. Nesse sentido, Lopes (2002), elenca capacidades esperadas no perfil dos egressos de cursos de engenharia, quais sejam uma sólida formação básica, o desenvolvimento do espírito crítico, a capacidade de resolver problemas teóricos e experimentais, a visão crítica do campo de trabalho, uma formação humanista e cultural e a autonomia intelectual. É necessário que as instituições de ensino acompanhem essa tendência para formar indivíduos que se adequem aos novos paradigmas (PÓVOA; BENTO, 2005).

\section{$O$ perfil do egresso de Engenharia Mecânica da UFC}

Visando a avaliar as contribuições do Projeto Pedagógico de Curso aprovado em 2004, foi realizada a coleta de informações apenas dos egressos que cursaram Engenharia Mecânica integralmente sob sua vigência, ou seja, os alunos que ingressaram no curso a partir do ano de 2005. Este universo de pesquisa corresponde a 311 alunos, constantes da lista obtida pelo SIGAA, dos quais 117 responderam à pesquisa. Os dados para análise foram obtidos via questionário, enviado prioritariamente por e-mail. Segundo Chaves (2016) e Freitas (2013), considera-se essa amostra nãoprobabilística, a qual não possui rigor estatístico, e os respondentes são selecionados por suas disponibilidades, assumindo os resultados como passíveis de representar o universo total.

O questionário consistiu em 26 perguntas, das quais quatro eram não obrigatórias. Do total de perguntas, 24 eram objetivas, sendo as 2 últimas, reservadas a opiniões e sugestões, subjetivas para os respondentes. Ele foi enviado após um teste com alunos próximos, para que pudesse ser aprimorado através de sugestões e feedback, por meio das quais foi finalizada a versão definitiva, que se encontra no apêndice ao final do documento.

\section{Perfil dos respondentes}

A primeira pergunta tratou do gênero dos respondentes. Pelos dados do Anuário Estatístico UFC 2019, no ano de 2018 a distribuição entre gênero dos estudantes matriculados era de $57 \%$ homens e $43 \%$ mulheres. Entre as respostas, houve uma grande discrepância, com um número muito mais proeminente de egressos do sexo masculino. Do total, $88 \%$ dos respondentes foram do sexo masculino e os $12 \%$ restantes do sexo feminino. Do mesmo modo, pode-se notar uma certa variação se comparado com a distribuição no total de alunos pesquisados no período, pois, do total de alunos do sexo feminino seria de apenas $8 \%$, frente a $92 \%$ de alunos do sexo masculino.

A segunda pergunta foi a respeito da idade. A faixa dominante foi de 25 a 28 anos, o que correspondeu a $50 \%$ dos alunos, seguida pelos alunos com mais de 28 anos com $35 \%$.

Foi perguntado também o ano de formatura dos respondentes. Conforme visto na Figura 1, as respostas corresponderam, em sua maioria, a alunos que se formaram no ano de 2018, sendo eles 31 respondentes, equivalendo a $26,5 \%$ do total. 
Figura 1 - Ano de formatura dos respondentes

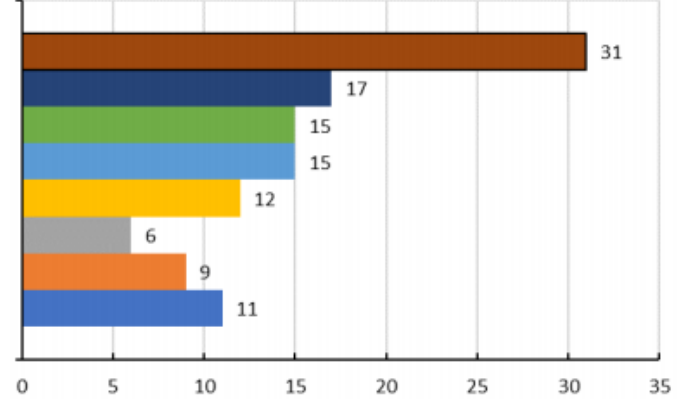

$$
\begin{aligned}
& \text { | } 2018 \\
& \text { = } 2017 \\
& \text { = } 2016 \\
& =2015 \\
& =2014 \\
& =2013 \\
& =2012 \\
& \text { = Até } 2011
\end{aligned}
$$

Fonte: elaborada pelos autores.

Ao analisar a etnia dos respondentes, Chaves (2016) compara a frequência com dados do IBGE. Segundo o IPECE, em sua análise da etnia da população cearense com base no Censo de 2010, a população está subdividida em $61,88 \%$ de pardos, $32 \%$ sendo de brancos e apenas $6,13 \%$ de afrodescendentes, asiáticos e indígenas. Pela Figura 2, pode-se ver que, entre os respondentes do presente trabalho, $55 \%$ se declararam brancos, enquanto $43 \%$ se declararam pardos e apenas $2 \%$ das etnias restantes. Nota-se um contraste entre as distribuições, mesmo com a política de cotas vigente desde o ano de 2012.

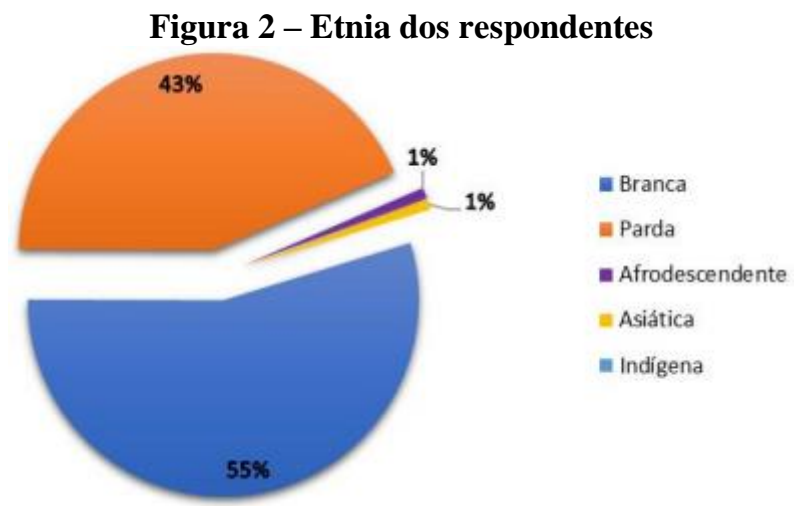

Fonte: elaborada pelos autores.

\section{Carreira acadêmica}

A pergunta inicial a respeito da carreira acadêmica foi sobre o domínio de idiomas estrangeiros. No questionário foi dada a possibilidade de responder mais de uma alternativa. Pode-se observar os resultados na Figura 3.

\section{Figura 3 - Domínio de idiomas}

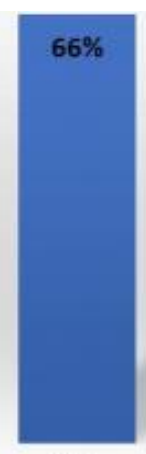

Inglês

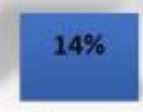

Francês

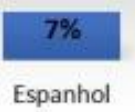

Espanhol

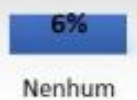

Nenhum

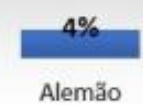

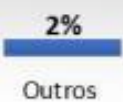

Fonte: elaborada pelos autores.

Os egressos também foram perguntados quanto às suas experiências extracurriculares. Notou-se que $68 \%$ dos respondentes participaram de laboratórios ou projetos de pesquisa. Em seguida, percebeu-se um número grande de respostas sobre intercâmbio (37\%). Entre os projetos de extensão, foram predominantes o PET e o projeto Mini-Baja. 
Figura 4 - Atividades acadêmicas dos respondentes
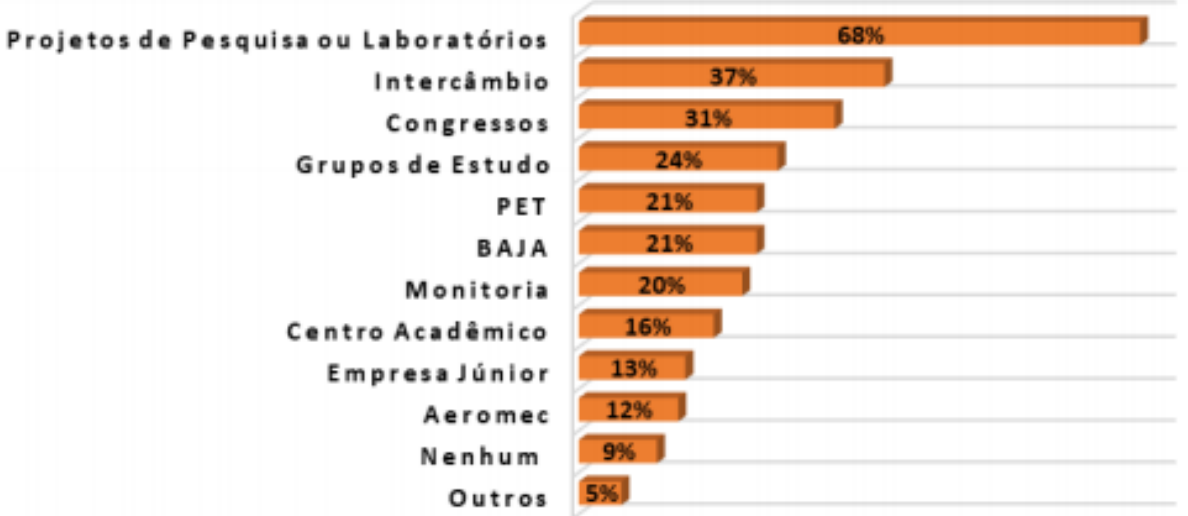

Fonte: elaborada pelos autores.

Do total de respondentes, apenas 10\% cursou ensino técnico. Possuir grau técnico pode ser um diferencial na busca por estágios e emprego, porém percebeu-se que a maioria dos alunos pesquisados $(90 \%)$ é oriunda do ensino médio tradicional.

Em seguida, foi perguntado em que tipo de instituição os respondentes haviam estagiado. A maioria (61\%) teve experiência com estágio em empresa privada. Além disso, pode-se verificar que, dentre os respondentes, $28 \%$ estagiaram mais de uma vez durante a graduação. Do total, $72 \%$ tiveram apenas uma experiência de estágio, e destes, no entanto, $18 \%$ tiveram como única experiência de estágio os laboratórios didáticos, graduando-se sem contato com o trabalho em empresas. Ressaltase que, pelo Anuário Estatístico UFC 2019, em 2018, 38\% dos alunos matriculados no curso estavam estagiando.
Figura 5 - Ramo de estágio feito pelos respondentes

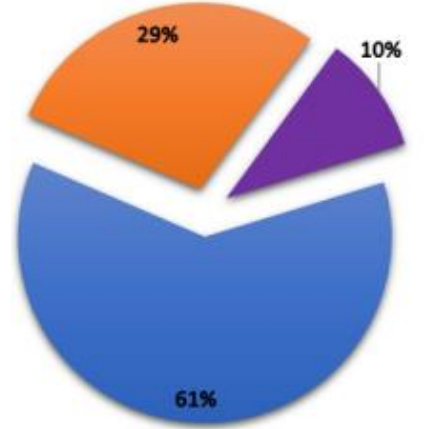

- Em empresa privada = Em laboratório de pesquisa no setor público

Fonte: elaborada pelos autores.

Quando indagados sobre a realização de pós-graduação, percebe-se que a maioria fez ou está fazendo alguma modalidade, podendo-se observar os resultados na Figura 6.

Figura 6 - Nível de especialização dos respondentes

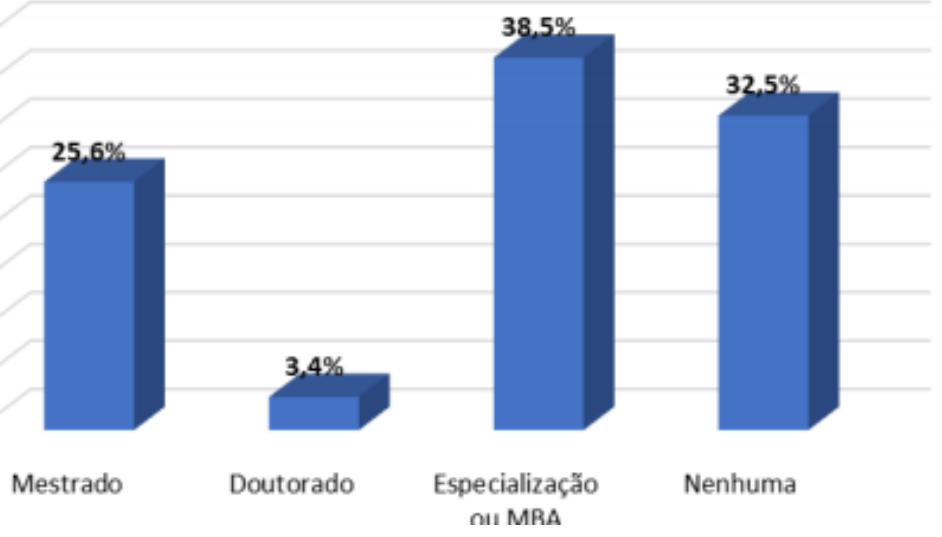

Fonte: elaborada pelos autores. 


\section{Carreira profissional}

Foi perguntada a situação atual dos respondentes. Conforme a Figura 11, a maioria está trabalhando $(57 \%)$ ou trabalhando e estudando (24\%) - portanto, $81 \%$ encontram-se inseridos no mercado - enquanto $19 \%$ dos respondentes está apenas estudando.

Figura 7 - Tipo de ocupação dos respondentes

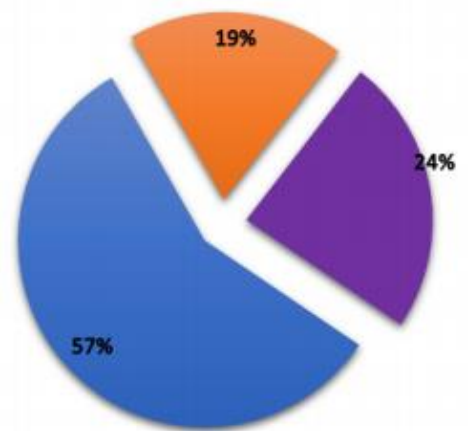

w Trabalhando

= Estudando

- Trabalhando e estudando

Fonte: elaborada pelos autores.

Os respondentes foram perguntados se já trabalharam com engenharia, sendo que $26 \%$ não teve contato com engenharia após se graduarem, o que pode ser devido a trabalharem em outros ramos ou mesmo ainda estarem estudando. Dentre aqueles que não trabalham com engenharia, pode se verificar que metade, $50 \%$, estão no momento apenas estudando.

Pela Figura 8, vê-se que $57 \%$ afirmou trabalhar em Fortaleza ou na região metropolitana, $23 \%$ trabalham em outros estados, e apenas 5\% trabalha no interior do Ceará.

Figura 8 - Região de trabalho dos respondentes

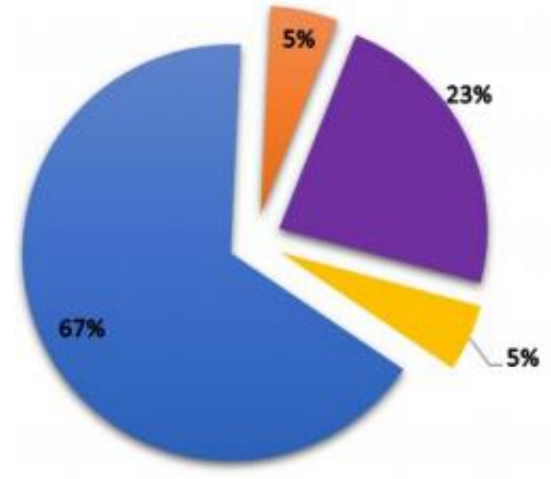

- Fortaleza ou regi metropolitana

w Interior do Ceará

- Em outros estado

In No exterior

Fonte: elaborada pelos autores.

Em seguida, buscou-se definir a distribuição entre setores econômicos. Conforme a Figura 9, em primeiro lugar está o setor industrial, o que era esperado devido à natureza da profissão. Em seguida está o setor de serviços e o setor público.

Figura 9 - Setor econômico onde trabalham

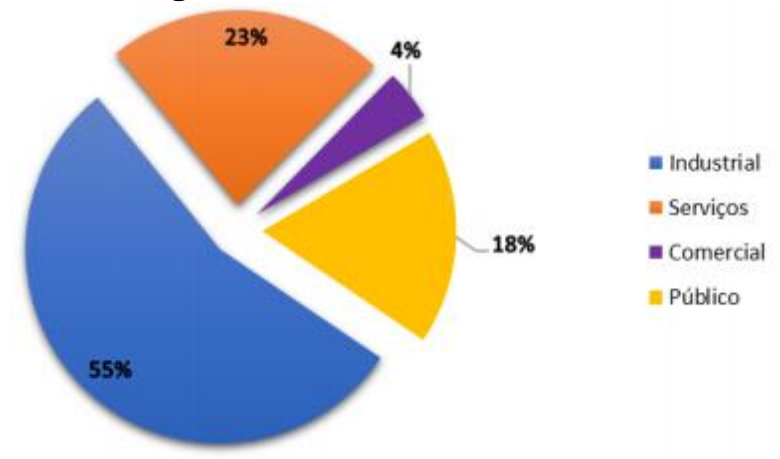

Fonte: elaborada pelos autores.

A pergunta seguinte tratava da forma de ingresso dos egressos no trabalho. Conforme a Figura 10, nota-se que as opções de empresa própria e empreendimento familiar receberam poucas respostas, o que mostra um caráter pouco empreendedor. Houve também respostas referentes a contratações devido aos bons resultados em programas de pós-graduação, que ficaram na categoria "outros".

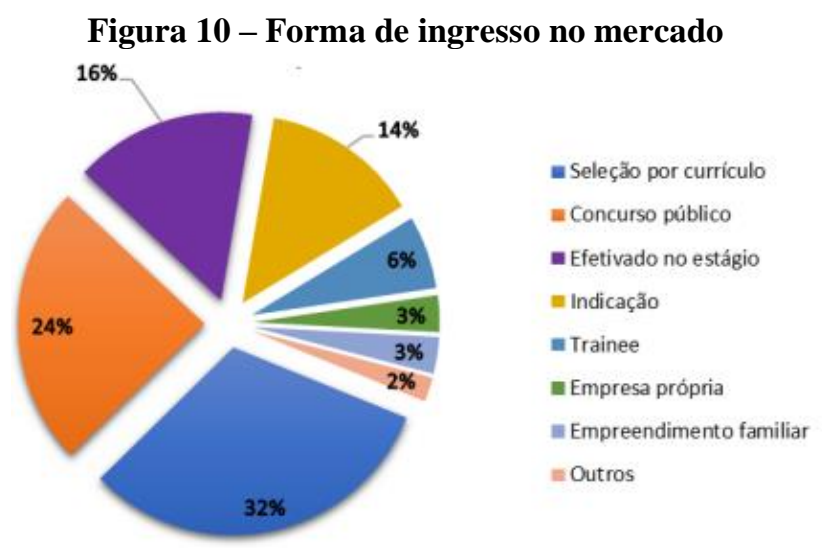

Fonte: elaborada pelos autores.

Quanto ao tempo de inserção no mercado, nota-se, pela Figura 11, que $58 \%$ dos respondentes foram contratados imediatamente, enquanto os que foram contratados em até 6 meses correspondeu a $23 \%$, e em até 1 ano, $8 \%$. O número de respondentes que ingressou no mercado em 
mais de um ano, no entanto, ainda é expressivo, com $11 \%$ das respostas.

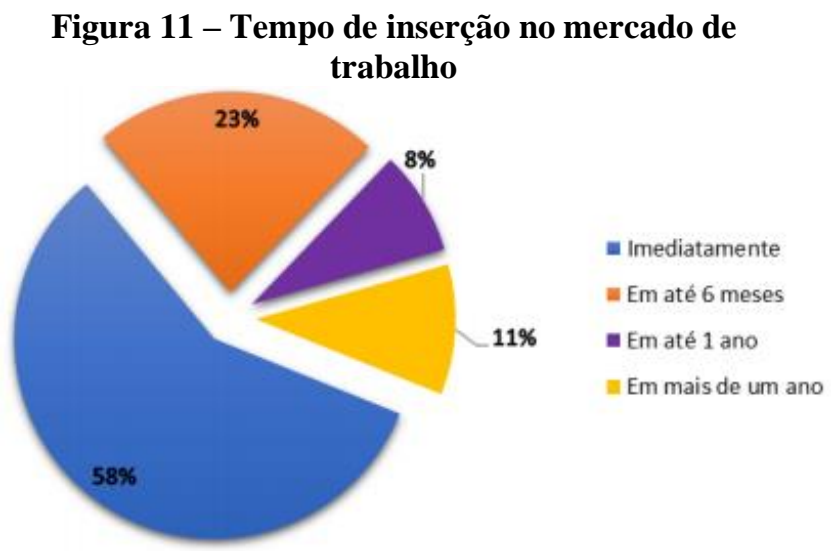

Em seguida, perguntou-se o tipo de cargo no qual se encontram. Quanto ao nível hierárquico, como visto na Tabela 1 , houve proximidade entre os níveis de analista e engenheiro, com $31 \%$ e $30 \%$ respectivamente, sendo que o cargo de analista demonstrou obter bastante representatividade.

Fonte: elaborada pelos autores.

Tabela 1 - Nível hierárquico dos respondentes

\begin{tabular}{|l|r|r|}
\hline \multicolumn{3}{|c|}{ Nível Hierárquico } \\
\hline & Respostas & Frequência Relativa \\
\hline Analista & $\mathbf{2 9}$ & $\mathbf{3 1 \%}$ \\
\hline Engenheiro & $\mathbf{2 8}$ & $\mathbf{3 0 \%}$ \\
\hline Outros & $\mathbf{1 1}$ & $\mathbf{1 2 \%}$ \\
\hline Gestor/Coordenador/Supervisor & $\mathbf{9}$ & $\mathbf{1 0 \%}$ \\
\hline Gerente & $\mathbf{6}$ & $\mathbf{6 \%}$ \\
\hline Consultor & 5 & $\mathbf{5 \%}$ \\
\hline Trainee & $\mathbf{5}$ & $\mathbf{4 \%}$ \\
\hline Diretor & $\mathbf{1}$ & $\mathbf{1 \%}$ \\
\hline Sócio/Proprietário & $\mathbf{1}$ & $\mathbf{1} \%$ \\
\hline
\end{tabular}

Fonte: elaborada pelos autores.

Os respondentes também foram indagados a respeito da sua faixa de rendimentos; obtevese 93 respostas. Chaves (2016) analisa a distribuição da faixa salarial sob vários aspectos, alguns dos quais são mostrados a seguir.

Figura 12 - Faixa salarial dos respondentes

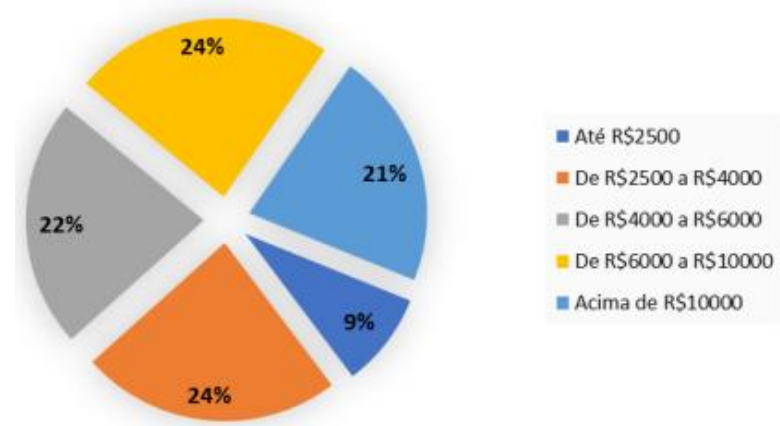

Fonte: elaborada pelos autores.

Em seguida, pode-se comparar a faixa de salário dos respondentes com seu ano de formatura. É possível perceber que há a tendência dos alunos formados há mais tempo terem, em sua maioria, uma faixa salarial mais elevada, com $60 \%$ dos formados até 2011 recebendo mais que 10 mil reais. Isso destaca a progressão em suas carreiras.

Chaves (2016) analisa a distribuição dos salários por gênero. A tabela 2, a seguir, mostra que, embora não tão acentuada, poderia haver uma discrepância entre o salário de homens e mulheres.

Tabela 2 - Faixa salarial comparado com gênero

\begin{tabular}{|l|r|c|r|r|}
\hline & \multicolumn{2}{|c|}{ Homens } & \multicolumn{2}{c|}{ Mulheres } \\
\hline & Freq. & \multicolumn{1}{c|}{$(\%)$} & Freq. & $(\%)$ \\
\hline Até R\$2500 & 7 & $8 \%$ & 1 & $11 \%$ \\
\hline De R\$2500 a R\$4000 & 19 & $23 \%$ & 3 & $33 \%$ \\
\hline De R\$4000 a R\$6000 & 19 & $23 \%$ & 2 & $22 \%$ \\
\hline $\begin{array}{l}\text { De R\$6000 a } \\
\text { R } \$ 10000\end{array}$ & 21 & $25 \%$ & 1 & $11 \%$ \\
\hline Acima de R\$10000 & 18 & $21 \%$ & 2 & $22 \%$ \\
\hline Total & 84 & $100 \%$ & 9 & $100 \%$ \\
\hline
\end{tabular}

Fonte: elaborada pelos autores. 
No entanto, assim como o fez Chaves (2016), foi necessária analisar a distribuição mais a fundo, devido à diferença significante entre a quantidade de respondentes homens e mulheres. Obteve-se poucas respostas de exalunas, em comparação com o total, sendo estas predominantemente formadas em anos mais recentes, onde se esperam faixas salariais mais baixas, enquanto em alguns anos não foram sequer conseguidas respostas. No caso dos homens, obteve-se uma distribuição mais uniforme, com um maior número de respostas de ex-alunos mais antigos, que possuíam faixas salariais mais elevadas. Desse modo, uma comparação mais assertiva ficou prejudicada, não sendo possível tomar conclusões mais concretas.

\section{Opiniões e percepções}

A seção seguinte do questionário tratou a respeito das percepções e opiniões sobre o curso em geral, formação de novos engenheiros e condições de mercado. Primeiramente, foi perguntado como os respondentes avaliavam as oportunidades de trabalho e desenvolvimento profissional para engenheiros mecânicos no Ceará. Algumas justificativas para esse resultado poderiam ser os salários mais baixos pagos no Ceará, além do fato de haver menos oportunidades de seguir carreira como engenheiro, ao invés de analista.

\section{Figura 13 - Oportunidades no Ceará}

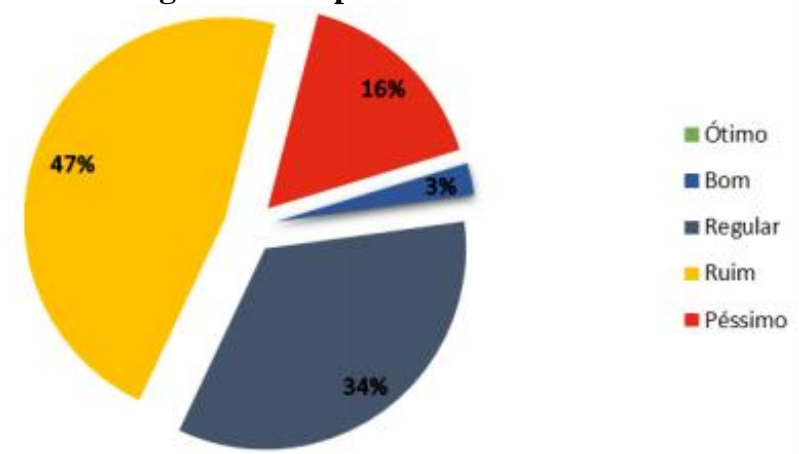

Fonte: elaborada pelos autores.

Em seguida, foi perguntada a opinião dos egressos sobre o que faltaria aos alunos recémformados de engenharia mecânica, com respeito à sua formação, sendo possível escolher mais de uma opção.

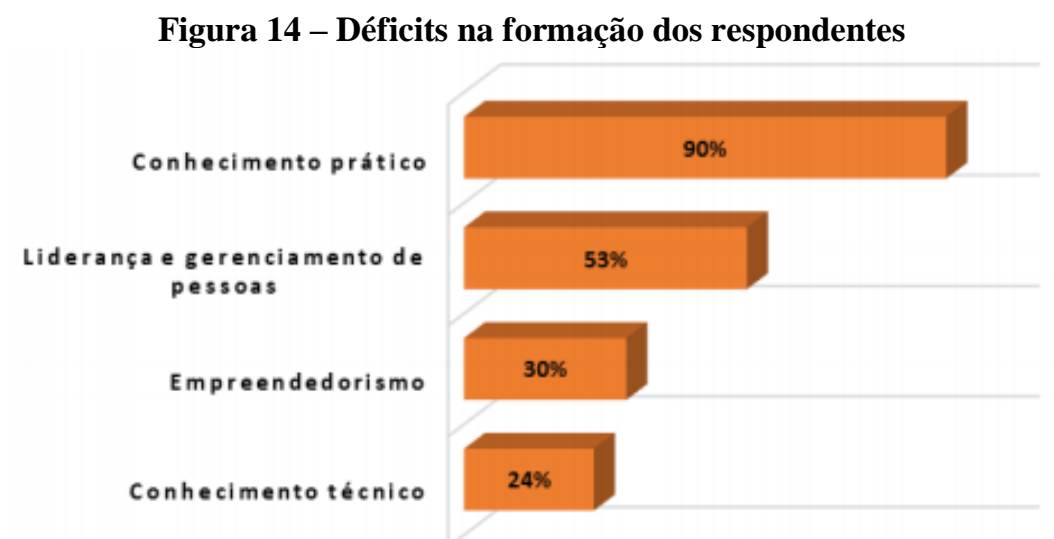

Fonte: elaborada pelos autores.

De modo semelhante ao trabalho de Chaves (2016), o conhecimento prático figura como fator mais significativo. Em seguida está liderança e gerenciamento de pessoas, com $53 \%$ e empreendedorismo com $30 \%$. Por último figurou conhecimento técnico, com $24 \%$.

$\mathrm{Na}$ sequência, perguntou-se, conforme a Figura 15, se houve e quais seriam as principais dificuldades enfrentadas pelos respondentes após se graduarem. Era possível marcar mais de uma opção, assim como havia espaço para inserir outras dificuldades que não estivessem listadas e que eles pudessem ter sentido. 
Figura 15 - Dificuldades dos respondentes após a graduação

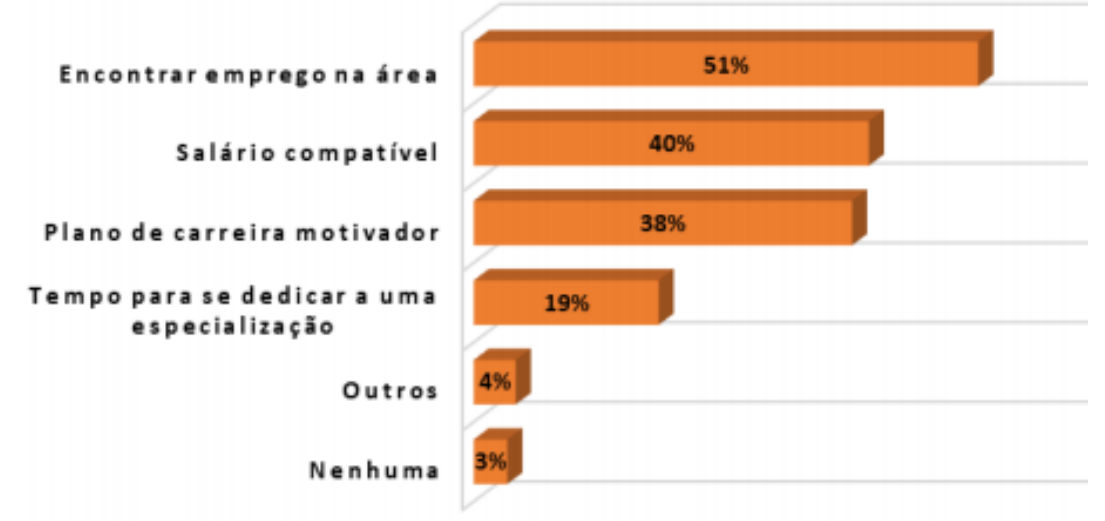

Fonte: elaborada pelos autores.

No presente trabalho, $51 \%$ dos egressos de engenharia mecânica relatam ter tido dificuldades em encontrar empregos na área, número muito maior que aquele apontado no trabalho de Chaves, $14 \%$. Uma razão para isso pode ser uma mudança do perfil de engenheiro buscado atualmente para profissionais mais generalistas, assim como uma fragilidade na indústria tradicional local.

Figura 16 - Áreas a serem melhor abordadas na graduação

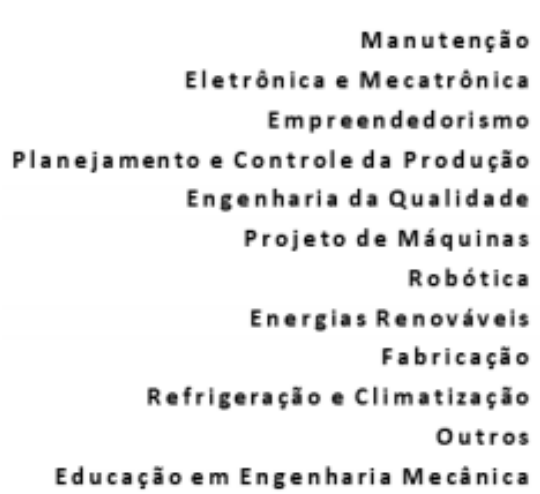

Fonte: elaborada pelos autores.

Os respondentes demonstraram ser necessária uma maior ênfase no ensino relacionado à área de manutenção, a qual também foi a área na qual a maioria deles já teve algum tipo de experiência profissional, o que pode denotar alguma defasagem entre o seu ensino no curso e sua importância no mercado de trabalho.

Por fim, foram perguntadas as opiniões dos egressos sobre como o currículo do curso e como os professores influenciaram e contribuíram para sua inserção no mercado de trabalho.

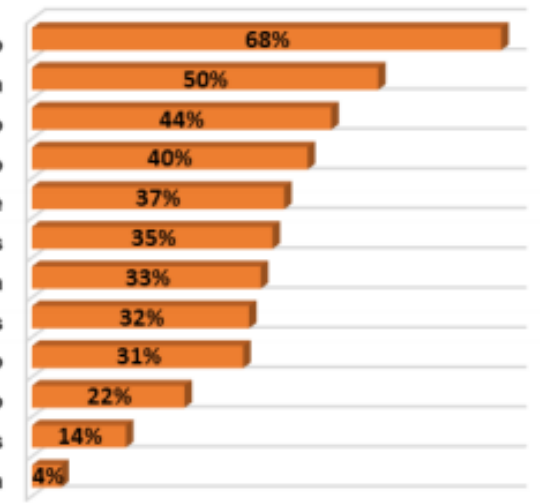

Fonte: elaborada pelos autores.
A seguir, foram questionadas quais áreas que, na visão dos respondentes, poderiam ter sido melhor abordadas durante a graduação. Levou-se em conta a grade curricular para definir as opções, além de uma opção aberta, para que fosse possível elencar outras áreas.

Figura 17 - Contribuição do currículo na formação dos egressos

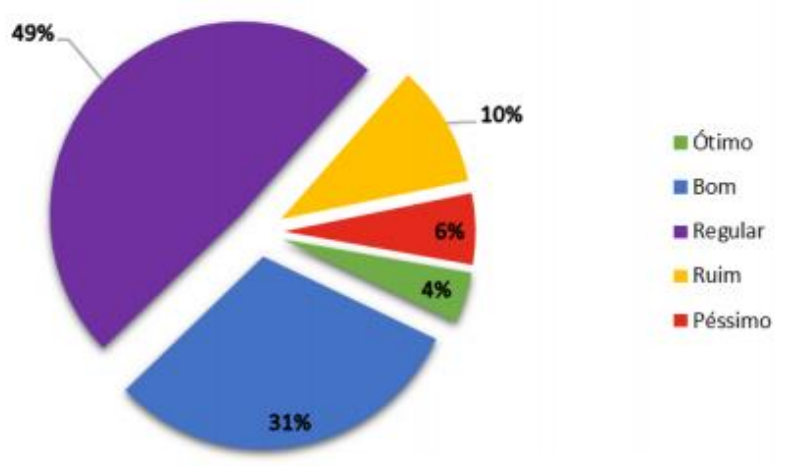




\section{Sugestões dos respondentes}

Por fim, para que fosse possível que os respondentes discorressem mais abertamente sobre suas percepções do curso de engenharia mecânica e sua formação, lhes foi perguntado se teriam sugestões de mudanças e melhorias para o curso e se gostariam de dar algum conselho para os atuais e futuros graduandos.

A seguir são elencadas alguma das sugestões que os respondentes sugeriram: ter abordagens mais práticas; aulas práticas de fabricação e ensino de softwares de modelagem; revisão do plano pedagógico; maior direcionamento para o mercado; focar mais na aplicabilidade.

Em relação ao aproveitamento dos laboratórios, foi pedido o seguinte: melhorar a infraestrutura dos laboratórios e a integração com a comunidade industrial; intensificar a interação das disciplinas com os respectivos laboratórios dentro da universidade.

As mudanças pedidas no currículo e estágio foram: aulas mais voltadas para o que é exigido no mercado de trabalho; introduzir cadeiras de gestão de pessoas e liderança; diversificar os horários da disciplina para oferecer horários alternativos para quem estagia.

\section{CONCLUSÃO}

A pesquisa mostrou que o profissional formado pela UFC supre principalmente a indústria cearense, porém, não obstante, também encontra espaço nos outros setores econômicos. De outros ramos da engenharia a áreas diversas, o egresso tem se inserindo relativamente rápido no mercado de trabalho. Entre suas áreas de maior atuação, temos as áreas de manutenção e projetos mecânicos. É um profissional que possui perspectivas de crescimento em sua carreira, apesar de muitos não trabalharem, pelo menos inicialmente, no cargo de engenheiro. Atuam principalmente na capital do estado, apesar de, nela, em comparação com outros estados, os salários em geral serem mais baixos. São sobretudo funcionários do setor privado; há, no entanto, muitos que optam pelo serviço público, pois as condições de trabalho são notadamente superiores, assim como o salário.

Em se tratando de formação, os engenheiros mecânicos oriundos da UFC, em geral, têm seu primeiro contato com práticas de engenharia na faculdade, o que os leva em grande número a suprir tal condição em laboratórios ou projetos de pesquisa, além de participarem dos diversos projetos de extensão do curso. Ainda assim, existem alunos que se graduam sem ter contato com a indústria por meio de estágios, tendo como única experiência prática a participação em tais projetos. Um grande número progride nos estudos, buscando especializações e pós-graduação para complementar sua formação.

As suas percepções como profissionais são de grande importância para o cumprimento da missão do departamento, pois, por meio delas, pode-se buscar aproximar o projeto políticopedagógico do curso das necessidades do mercado que eles integram, e, assim, formar engenheiros mais capazes de lidar com os desafios atuais.

Por fim, foram sugeridas oportunidades de melhoria para um futuro PPC, baseando-se nos dados obtidos. O acompanhamento dos egressos é uma ferramenta muito útil para conduzir mudanças no curso de engenharia mecânica. Sugere-se que seja feito de maneira mais regular, de maneira complementar com pesquisas semelhantes com os alunos que estejam atualmente se graduando.

\section{REFERÊNCIAS}

CENTRO DE TECNOLOGIA DA UNIVERSIDADE FEDERAL DO CEARÁ. Apresentação e histórico do CT. Disponível em: $\quad<$ https://ct.ufc.br/sobre-o-centrodetecnologia/apresentacao-e-historico-do-ct/> Acesso em: 10 out. 2019.

CHAVES, A. F. Proposta de oportunidades de melhoria para o curso de bacharelado em engenharia de produção mecânica da UFC: um estudo a partir do acompanhamento de egressos. 2016. Trabalho de Conclusão de Curso (Graduação em Engenharia de Produção 
Mecânica) - Universidade Federal do Ceará, Fortaleza/Ceará, 2016.

DEPARTAMENTO DE ENGENHARIA ELÉTRICA DA UNIVERSIDADE FEDERAL DO RIO DE JANEIRO. História da escola de engenharia. Disponível em: http://www.dee.ufrj.br/inicio_arquivos/Engen haria-Eletrica-UFRJ_arquivos/Historico.htm Acesso em: 10 out. 2019.

INSTITUTO DE PESQUISA E ESTRATÉGIA ECONÔMICA DO CEARÁ (IPECE). Perfil da raça da população cearense: análise a partir dos dados do Censo Demográfico $2010 . \quad$ Disponível em: $<$ https://www.ipece.ce.gov.br/wp58content/uploads/sites/45/2012/12/Ipece_Inf orme_23_fevereiro_2012.pdf> Acesso em: 31 out. 2019

HOBSBAWN, E. J. A Era das Revoluções. Trad. Maria Tereza Teixeira e Marco Penchel. São Paulo: Paz e Terra, 2015.

INEP. Sinopses estatísticas da educação superior. Disponível em: <http://inep.gov.br/sinopsesestatisticas-da-educacao-superior $>$ Acesso em: 10 out. 2019.

\section{INSTITUTION OF MECHANICAL ENGINEERS} (IMechE). History of the institution of mechanical engineers. Disponível em: $<$ https://www.imeche.org/aboutus/imecheengineering-history/institution-andengineering-history> Acesso em: 10 out. 2019.

LOPES, J. de A. A formação do profissional na área de ciências exatas e engenharias: a necessidade de um projeto pedagógico consistente. Revista de Educação PUC-Campinas, Campinas, n. 12, p. 91-114, 2002. Disponível em: <https://periodicos.puccampinas.edu.br/seer/i ndex.php/reveducacao/article/view/327> Acesso em: 09 out. 2019.

MIRANDA, A. N. de et al. Memórias: cinquentenário da Escola de Engenharia. Fortaleza: LCR, 2005.

PÓVOA, J, M.; BENTO, P. E. G. O engenheiro, sua formação e o mundo de trabalho. Anais... XXXIII Congresso Brasileiro de Ensino de Engenharia-COBENGE, 2005.

UNIVERSIDADE FEDERAL DO CEARÁ. Anuário estatístico UFC 2019. Disponível em: $\quad<$ http://www.ufc.br/auniversidade/documentos-oficiais/322anuarioestatistico> Acesso em: 11 nov. 2019.

UNIVERSIDADE FEDERAL DO CEARÁ. Projeto político pedagógico do curso de engenharia mecânica. Disponível em: $<$ https://prograd.ufc.br/cursosdegraduacao/engenharia-mecanica-fortaleza/> Acesso em 10 out. 2019.

UNIVERSIDADE FEDERAL DO RIO DE JANEIRO. História da escola politécnica. Disponível em: <http://www.poli.ufrj.br/politecnica_historia.p hp> Acesso em: 10 out. 2019.

WICKERT, J.; LEWIS, K. E. Introdução à engenharia mecânica. São Paulo: Cengage Learning Edições Ltda., 2016.

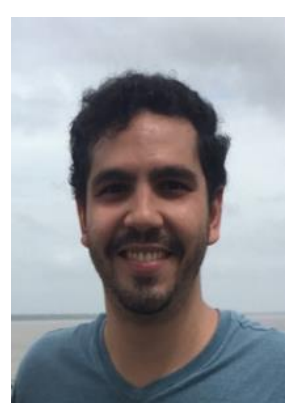

\section{DADOS BIOGRÁFICOS DOS AUTORES}

Pedro Vitor Teixeira Ribeiro - Graduado em Engenharia Mecânica pela Universidade Federal do Ceará (2019), com graduação-sanduíche na Universität Duisburg-Essen (2016). Foi membro da empresa júnior Diferencial Jr, na Universidade Federal do Ceará (UFC) e trabalhou como estagiário do Banco do Nordeste (BNB), com experiência nas áreas de manutenção e projeto de instalações. 

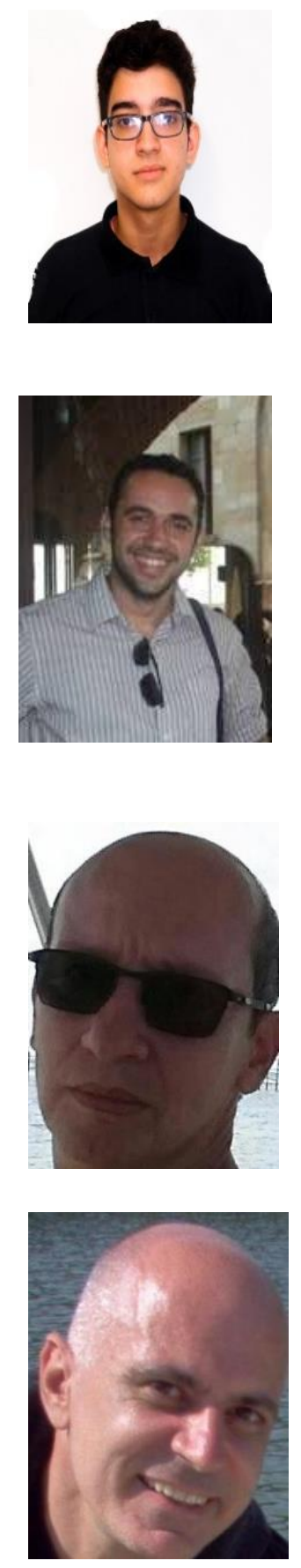

Victor Hugo Rodrigues Nogueira George - Graduando em Engenharia Mecânica pela Universidade Federal do Ceará desde 2019. Bolsista do Projeto de Apoio à Graduação pelo Departamento de Engenharia Mecânica da UFC e Capitão da Equipe Siará Baja (UFC).

Romulo do Nascimento Rodrigues - Graduação em Engenharia Mecânica pela Universidade Federal da Paraíba (2011), Mestrado pelo Programa de Pós-Graduação em Engenharia Mecânica da Universidade Federal de Campina Grande (2013) e Doutorado em Engenharia Mecânica pela Università di Pisa (Unipi), Pisa, Itália (2017). Atualmente é professor do magistério superior Adjunto da Universidade Federal do Ceará (UFC). Tem experiência na área de Engenharia Mecânica, com ênfase em Elementos de Máquinas, atuando principalmente nos seguintes temas: Tribologia, Vibrações, Análise de Sinais Vibratórios e Elementos Finitos. Atualmente realiza pesquisa nas áreas de Tribologia, Vibrações e análise com elementos finitos.

Roberto de Araújo Bezerra - Graduação em Engenharia Mecânica pela Universidade Federal do Ceará (1990), fez o Mestrado em Engenharia Mecânica pela Faculdade de Engenharia Mecânica de Uberlândia, Minas Gerais (1996) e Doutorado em Engenharia Mecânica pela Universidade Estadual de Campinas Unicamp, São Paulo (2004). Atualmente é professor Associado da Universidade Federal do Ceará. Tem experiência na área de Engenharia Mecânica, com ênfase em Elementos de Máquinas, atuando principalmente nos seguintes temas: Mecanismos, Vibrações, Análise de Sinais Vibratórios e Manutenção Preditiva.

Pierre Maurice Christophe Lamary - Possui graduação em Ciência Aeroespacial e Técnica pela Institut Polytechnique des Sciences Appliquées, science aérospatiale et tec (1986), mestrado em Elementos finitos, Modelização das Estruturas e FD pela Universitè de Technologie de Compiègne (1987), doutorado em Mecânica Aplicada - Acústica pela Universitè de Technologie de Compiègne (1990), pós-doutorado pela Universidade Estadual de Campinas(2005) e pós-doutorado pela Universidade Estadual de Campinas (2010). Atualmente é Professor da Universidade Federal do Ceará. Tem experiência na área de Engenharia Mecânica, com ênfase em Estruturas Aeroespaciais. Atuando principalmente nos seguintes temas: Aeronaves, FEM, BEM e Controle de Ruído. 